\title{
MULTI LAYER STACKED RECTANGULAR DIELECTRIC RESONATOR ANTENNA
}

\author{
Richa Gupta ${ }^{1}$, Mahender Singh $^{2}$, Arti Vaish $^{3}$, Ankit Gaur ${ }^{4}$ \\ E-Mail Id: richaguptamsit@gmail.com ${ }^{1}$, msingh5500@gmail.com² \\ ${ }^{1,4}$ Maharaja Surajmal Institute of Technology, GGSIPU, Delhi, India \\ ${ }^{2}$ Guru Tegh Bahadur Institute of Technology, Delhi, India \\ ${ }^{3}$ School of Engineering and Technology, Ansal University Haryana, India
}

\begin{abstract}
This paper present a design of stacked rectangular dielectric resonator antenna provides 52.57 degree beam width and gain $6.9 \mathrm{dBi}$ which operate in 5 to $8 \mathrm{GHz}$ range of frequencies by stacking of descending order of permittivity from 20 to 10 of $1.5 \mathrm{~mm}$ height of every block. A $50 \mathrm{ohm}$ microstrip line is employed in proposed antenna as feeding mechanism. A novel different beam aperture coupled DRA is proposed which consists of multi-layered rectangular geometry of ceramic disk of various dielectric constant joined to realize the specified height. The parameter of antenna is $15 \times 18 \times 1.5 \mathrm{~mm}^{3}$ with grounded substrate size: $50 \times 50 \mathrm{~mm}^{2}$. The proposed antenna is suitable for $\mathrm{C}$ and $\mathrm{X}$ band application.
\end{abstract}

Keywords: Rectangular DRA, Stack, Permittivity, Beam width.

\section{INTRODUCTION}

DRAs exhibit a wider impedance bandwidth and better radiation efficiency, especially at millimeter- wave frequencies where the conductor losses of metallic patches are considerable. One among the foremost crucial problems with conventional DRAs is that the dependence of their size and impedance bandwidth on the dielectric constant of material utilized in antennas. A DRA made up of a low permittivity material would have a comparatively large volume because of the inverse proportionality between effective wavelength and therefore the square root of the permittivity. It would, however, exhibit a low radiation Q-factor and thus a good impedance bandwidth[1-3]. Choice of dielectric constant of material utilized in the DRA is crucially important for wideband operation with compact design of the DRAs. Applications within the wireless and mobile communication areas require the event of radiating elements, which have as compact/low profile and wideband as possible. Hence, a great deal of research is directed towards a rise of the bandwidth of the DRAs while keeping the dimensions compact/low profile. Towards this goal, the technique of merging modes has proven to be very beneficial [4-6]. The essential concept relies on the excitation of multiple modes at nearby frequencies, in order that an overall wide impedance bandwidth will be achieved. A method is to mix the DRA modes with resonances of the feeding scheme. for example, an easy cylindrical DRA (CDRA) described in[4] is fed from a microstrip line through two parallel bowtie slots The second thanks to achieve the merging of modes is through the planning of the acceptable DRA geometry that ends up in the excitation of higher-order DRA modes[7-9] at nearby frequencies. Conceptually this technique is relatively simple, but it nevertheless comes along with an important issue, which needs to be taken into account.

The researchers are focusing on improving the gain along with getting the narrow beam and sustainable bandwidth for the satellite communication. The dielectric resonator antennas are the step forward to microstrip antennas with low metal loss, high radiation, high gain, etc. which creates the chance of more advanced antennas for different applications in satellite communication. In this paper different Rectangular stacking DRA geometries are analysed. The different dielectric constant material in increasing and decreasing order of permittivity is stacked together for improvement in gain and controlling beam-width of the antenna.

\section{ANTENNA GEOMETRY}

Figure 1(a) presents the geometry of a rectangular DRA using FR-4 epoxy substrate with a permittivity (cr) of 4.4.Ten rectangular layers each of height $1.5 \mathrm{~mm}$, making a total height of $15 \mathrm{~mm}$ and permittivity varying in increasing order from $11,12,13, \ldots .20$ is shown. The same stacked rectangular geometry is analysed in which stacking layer permittivity are varied in decreasing order from $20,19,10 \ldots \ldots \ldots 11$. All the dimensions are summarised in Table 2.1.

Table-2.1 Parametric Study of Different Geometry of DRA

\begin{tabular}{|c|c|c|c|c|c|c|}
\hline Ref. & Antenna Geometry & Freq $(\mathbf{G H z})$ & $\begin{array}{l}\text { Feeding } \\
\text { Technique }\end{array}$ & $\varepsilon_{r}$ & Gain(dBi) & $\begin{array}{c}\text { Beamwidth } \\
\text { (degree) }\end{array}$ \\
\hline [1] & $\begin{array}{l}\text { Stacked cylindrical dielectric } \\
\text { resonator antenna with meta } \\
\text { material used as substrate. }\end{array}$ & $\begin{array}{l}\left(8.49{ }^{-}\right. \\
10.61 \mathrm{GHz})\end{array}$ & Probe fed & & $12.86 \mathrm{~dB}$ & $33.5^{\circ}$ \\
\hline [2] & Cylindrical cup & $\begin{array}{l}37 \% \quad(7.8- \\
11.4 \mathrm{GHz})\end{array}$ & $\begin{array}{l}\text { L-shaped } \\
\text { probe }\end{array}$ & 10.2 & 5.5 & 70 \\
\hline [3] & perforated holes cylindric al DRA & $\begin{array}{l}8.18 \text { to } 10.7 \\
\mathrm{GHz}\end{array}$ & Probe fed & & & 53 \\
\hline
\end{tabular}




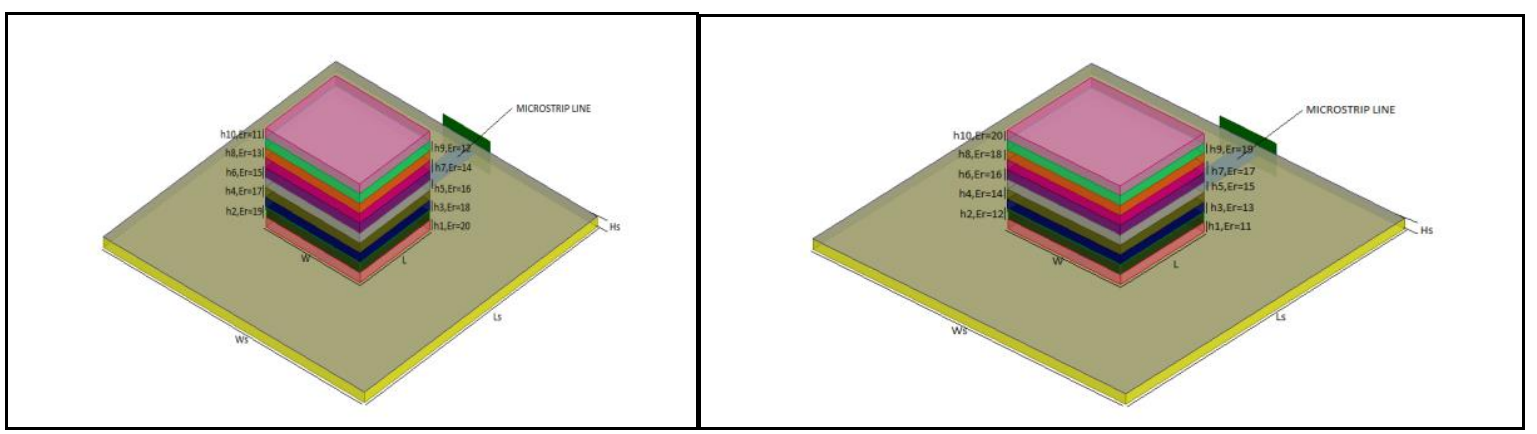

(a)

(b)

Fig. 2.1(a-b) Stacking of 10 Layers of Rectangular DRA with Height 1.5mm and Permitivity Increasing from 11,12,13....,20. and Decreasing $(20 \ldots .11)$

Table-2.2 Geometry of RDRA

\begin{tabular}{|l|l|l|}
\hline & Dimensions & Units \\
\hline Er substrate & 4.4 & \\
\hline Substrate Dimensions & $50 * 50 * 1.6$ & $\mathrm{Mm}$ \\
\hline Strip Line Dimensions & $31 * 3$ & $\mathrm{Mm}$ \\
\hline Slot Size & $1.568 * 7.84$ & $\mathrm{Mm}$ \\
\hline Stub Size & $5.216 * 3$ & $\mathrm{Mm}$ \\
\hline Length & 15 & $\mathrm{Mm}$ \\
\hline Width & 18 & $\mathrm{Mm}$ \\
\hline Height of each stack & 1.5 & $\mathrm{Mm}$ \\
\hline
\end{tabular}

Stacking of DRA on top of each other increases the impedance bandwidth. The effective height of the stacked RDRAis asimplesumof slabs' height

\section{MATHEMATICAL MODELLING}

$$
h=h_{1}+h_{2+} h_{3}+h_{4}
$$

The effective permittivity $\left(s_{\text {eff }}\right.$ ) of the proposed stacked RDRA is obtained as

$$
\epsilon_{e f f}=\frac{h}{\frac{h_{1}}{\epsilon_{r 1}}+\frac{h_{2}}{\epsilon_{r 2}}}
$$

The frequency of rectangular DRA as follows

$$
\begin{gathered}
f_{o}=\frac{c}{2 \pi \sqrt{\varepsilon_{r}}} \sqrt{k_{x}^{2}+k_{y}^{2}+k_{z}^{2}} \\
k_{x}^{2}+k_{y}^{2}+k_{z}^{2}=\varepsilon_{r} k_{o}^{2}
\end{gathered}
$$

Where, $k_{x}=m \frac{\pi}{a}, k_{y}=n \frac{\pi}{b}$, and $k_{z} \operatorname{tag}\left(k_{z} d / 2\right)=\sqrt{(\varepsilon r-1) k_{o}^{2}-k_{z}^{2}}$

\section{RESULTS AND ANALYSIS}

The $S_{11}$ vs frequency response of two geometries Rectangular with 10 layers stacking as a function of frequency with increasing and decreasing permittivity levels are shown in Fig. 2.1(a-b). It can be observed that bandwidth response of proposed antenna has multiple frequency resonance. Every geometry is investigated for understanding the antenna operation. This S11 graph of Stacked 10 layer with Inc. Permittivity of $11,12,13 \ldots \ldots$ ,20 shows that there are dips at $6.51 \mathrm{GHz}$ of $-15.97 \mathrm{~dB}, 6.8 \mathrm{GHz}$ of $-14.32 \mathrm{~dB}, 7.30 \mathrm{GHz}$ of $-16.32 \mathrm{~dB}$ having \%bandwidth 4.04\%, 2.64\%, 1.09\%. VSWR of Stacked 10-layer Inc. Permittivity of 11, 12, 13....., 20 RDRA is <2. This S11 graph of Stacked 10 layer with Dec. Permittivity of 11, 12, 13...,20 shows that there are dips at $5.54 \mathrm{GHz}$ of $-23.88 \mathrm{~dB}, 6.93 \mathrm{GHz}$ of $-11.13 \mathrm{~dB}, 7.83 \mathrm{GHz}$ of $-14.22 \mathrm{~dB}$ having $\%$ bandwidth $7.59 \%, 2.16 \%$, $5.75 \%$. VSWR of Stacked 10-layer Dec. Permittivity of 11, 12, 13..., 20 RDRA is <2. Gain of Stacked 10 layer Inc. Permittivity of $11,12,13 \ldots . ., 20$ RDRA is $5.93 \mathrm{dBi}$. Stacked 10 layer with Inc. Permittivity of 11, 12, 13...., 20 RDRA has beam width i.e. $77.80 \mathrm{~dB}$ and having Directivity of $4.33 \ldots$ Stacked 10 layer with Dec. Permittivity of $11,12,13 \ldots ., 20$ RDRA has beam width i.e. $52.57 \mathrm{~dB}$ and having Directivity of 5.24 . All the results are summarised in table. 
ICACCG2020 30-31 July, 2020, Ansal University, Gurgaon, India

International Journal of Technical Research \& Science (Special Issue)

Table-4.1Summarised Results

\begin{tabular}{|c|c|c|c|c|c|c|c|c|}
\hline & $\begin{array}{l}\text { S11 } \\
(\text { GHz })\end{array}$ & VSWR & $\begin{array}{l}\text { Z11 } \\
\text { (ohm) }\end{array}$ & $\begin{array}{l}\text { GAIN } \\
2 \mathrm{D}(\mathrm{dB})\end{array}$ & $\begin{array}{l}\text { Beam } \\
\text { Width } \\
\text { (dB 10) }\end{array}$ & $\begin{array}{l}\% \text { Band- } \\
\text { width }\end{array}$ & $\begin{array}{l}\text { Centre } \\
\text { frequency } \\
\text { (GHz) }\end{array}$ & $\begin{array}{l}\text { Directivity } \\
\text { (mag) }\end{array}$ \\
\hline $\begin{array}{l}10 \text { layer rectangular } \\
\text { Increasing } \\
\text { Permittivity } \\
(11,12 . . . .20) \\
\text { With height } \\
1.5 m m \text { each }\end{array}$ & $\begin{array}{l}6.3-6.56 \\
6.72-6.9 \\
7.26-7.34\end{array}$ & $<2$ & 66.09 & 5.93 & 77.80 & $\begin{array}{l}4.04 \% \\
2.64 \% \\
1.09 \%\end{array}$ & $\begin{array}{l}6.43 \\
6.81 \\
7.3\end{array}$ & 4.33 \\
\hline $\begin{array}{l}10 \text { layer rectangular } \\
\text { Decreasing } \\
\text { Permittivity } \\
(11,12 . . . .20) \\
\text { With height } \\
1.5 \mathrm{~mm} \text { each } \\
\end{array}$ & $\begin{array}{l}5.19-5.60 \\
6.85-7.0 \\
7.6-8.05\end{array}$ & $<2$ & 58.43 & 6.9 & 52.57 & $\begin{array}{l}7.59 \% \\
2.16 \% \\
5.75 \%\end{array}$ & $\begin{array}{l}5.395 \\
6.925 \\
7.825\end{array}$ & 5.24 \\
\hline
\end{tabular}

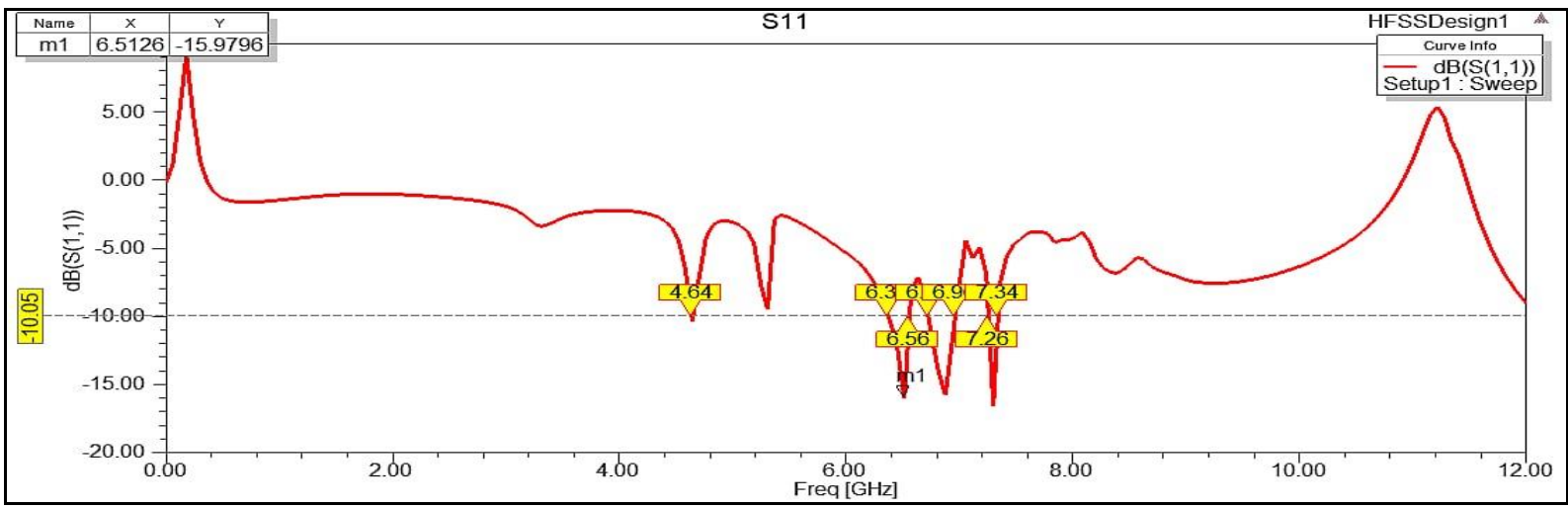

Fig. 4.1 S11 Stacked 10 layer Inc. Permittivity RDRA

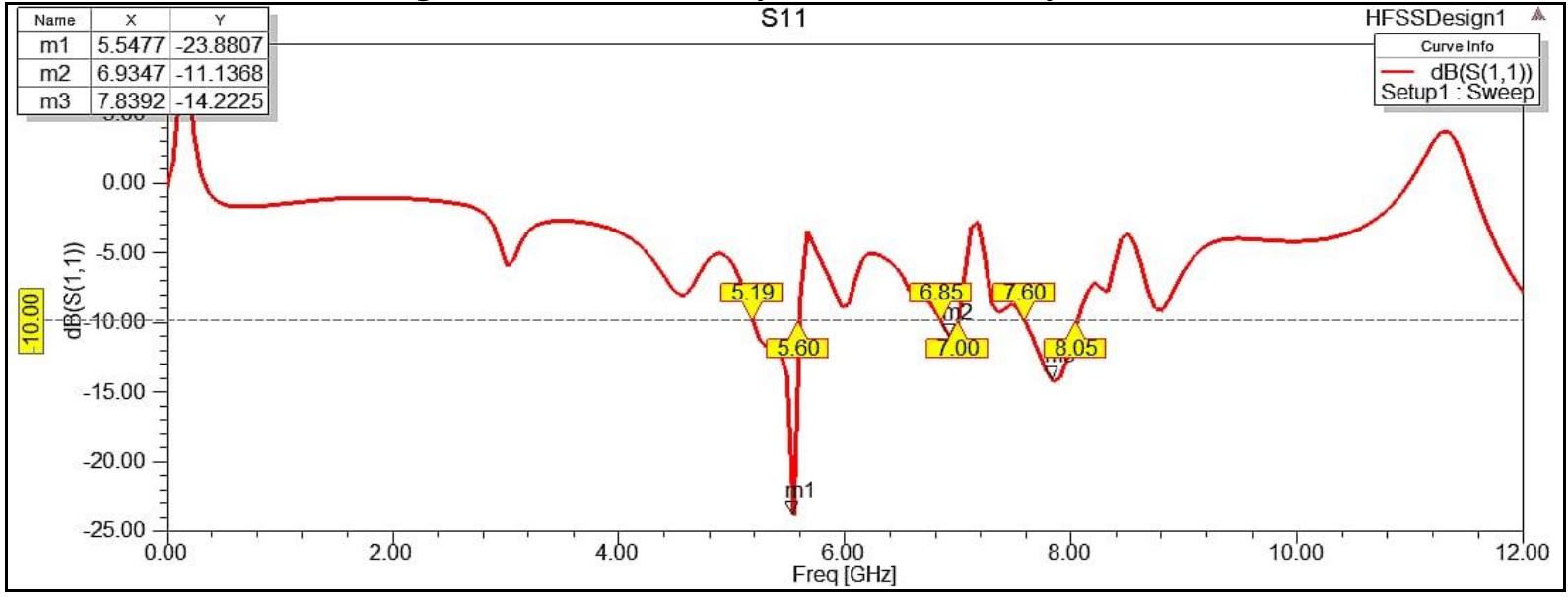

Fig. 4.2 S11 Stacked 10 layer Dec. Permittivity RDRA

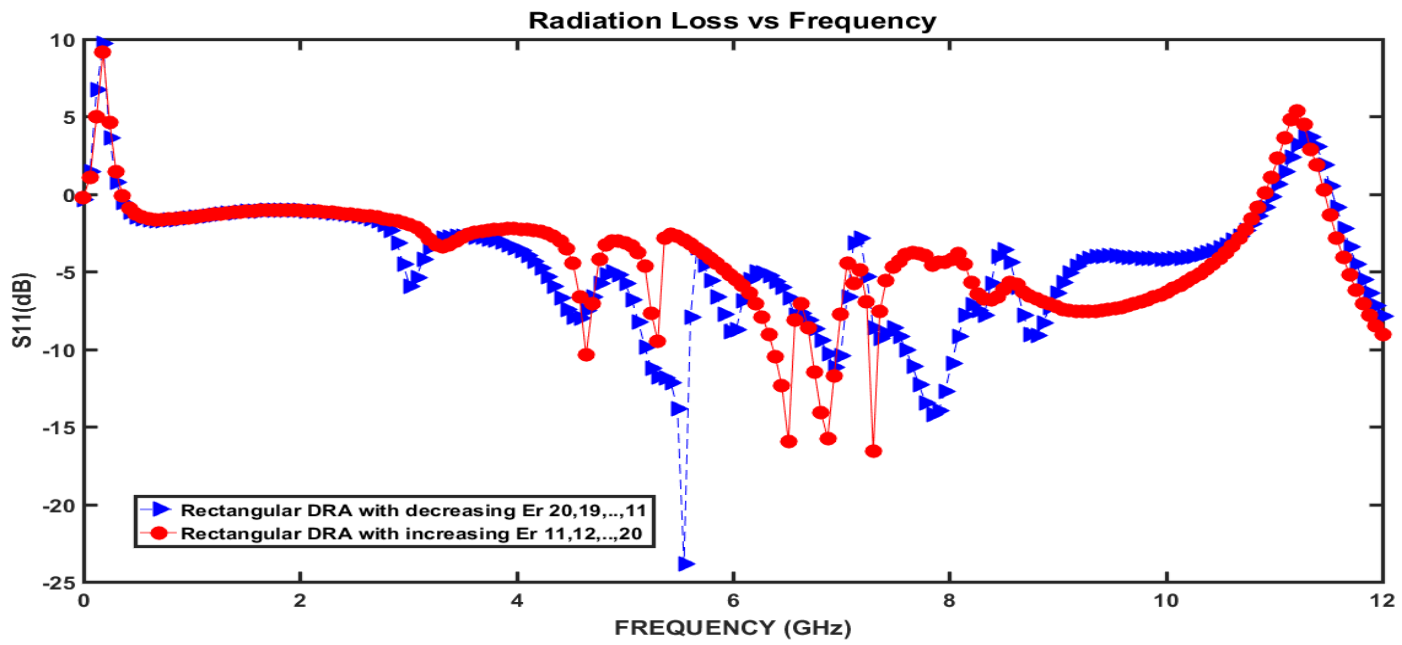

Fig. 4.3 S11 Stacked 10 layer Dec and inc. Permittivity RDRA

DOI Number: https://doi.org/10.30780/specialissue-ICACCG2020/005

Paper Id: IJTRS-ICACCG2020-005

pg. 30 @ 2017, IJTRS All Right Reserved, www.ijtrs.com 
ICACCG2020 30-31 July, 2020, Ansal University, Gurgaon, India

International Journal of Technical Research \& Science (Special Issue)

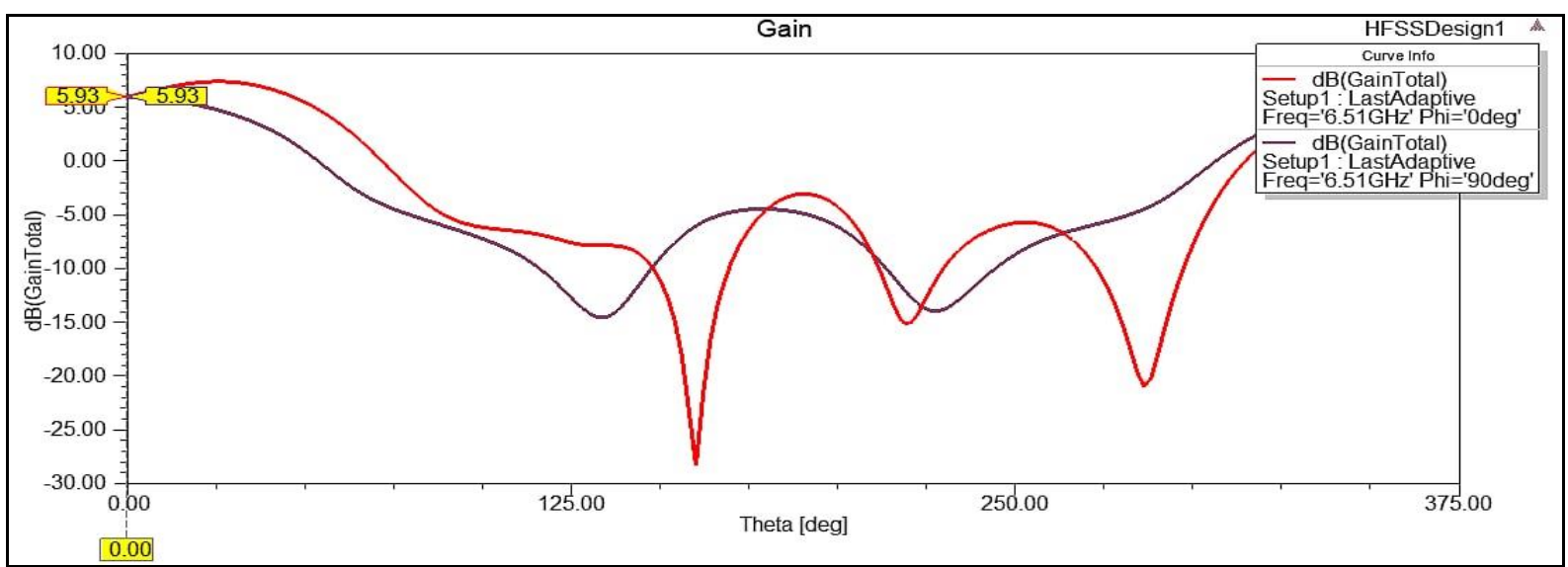

Fig. 4.4 Gain Stacked 10 Layer Inc. RDRA

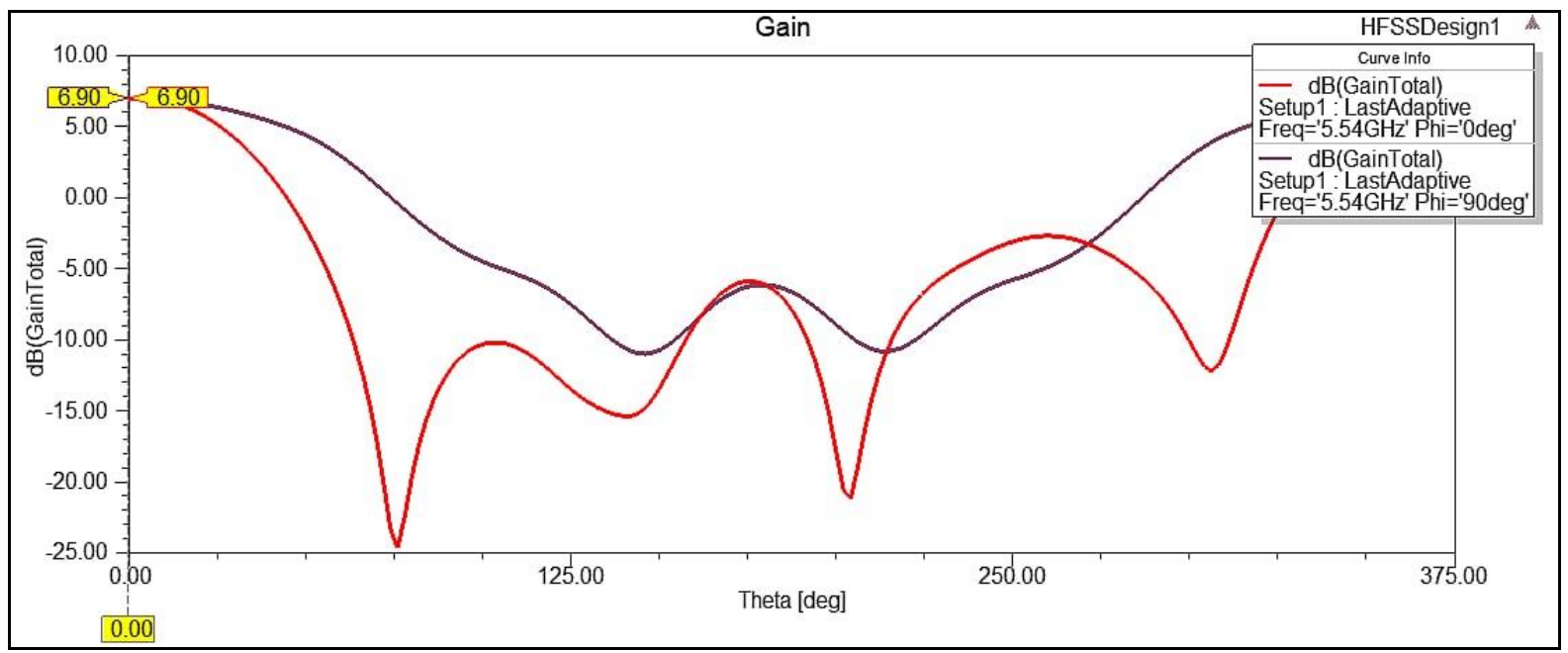

Fig. 4.5 Gain Stacked 10 Layer Decreasing Permittivity RDRA

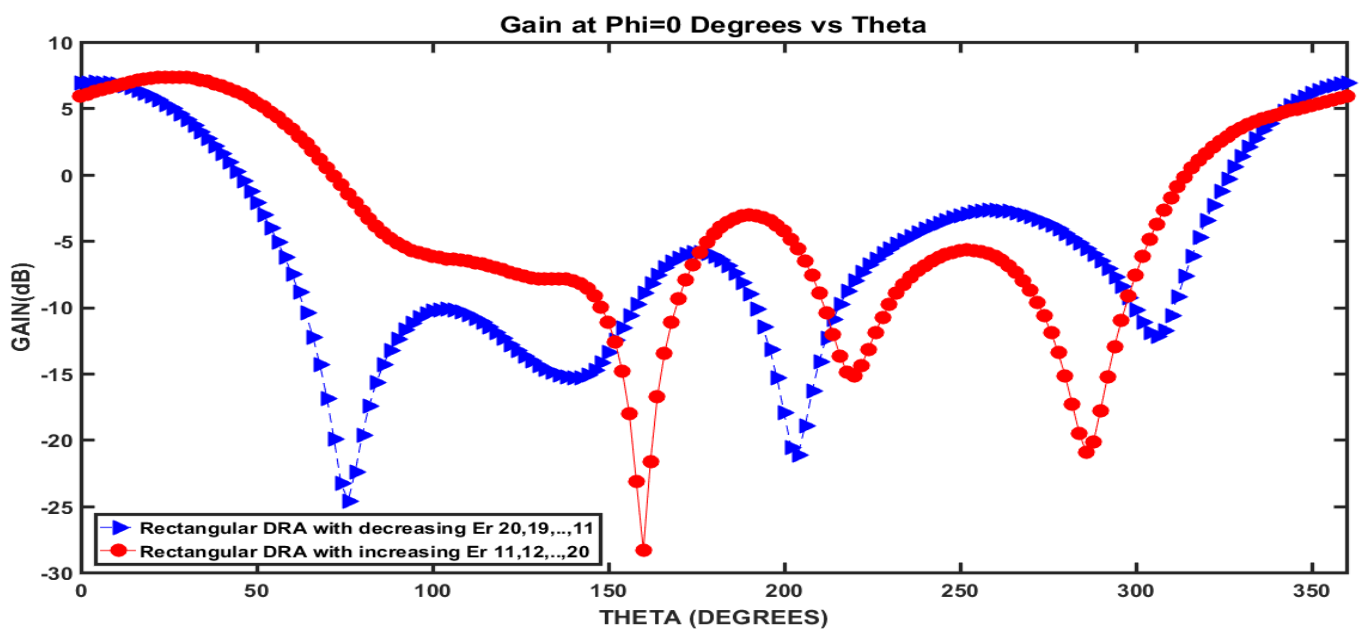

Fig. 4.6 Gain Stacked 10 Layer Dec and inc. Permittivity RDRA

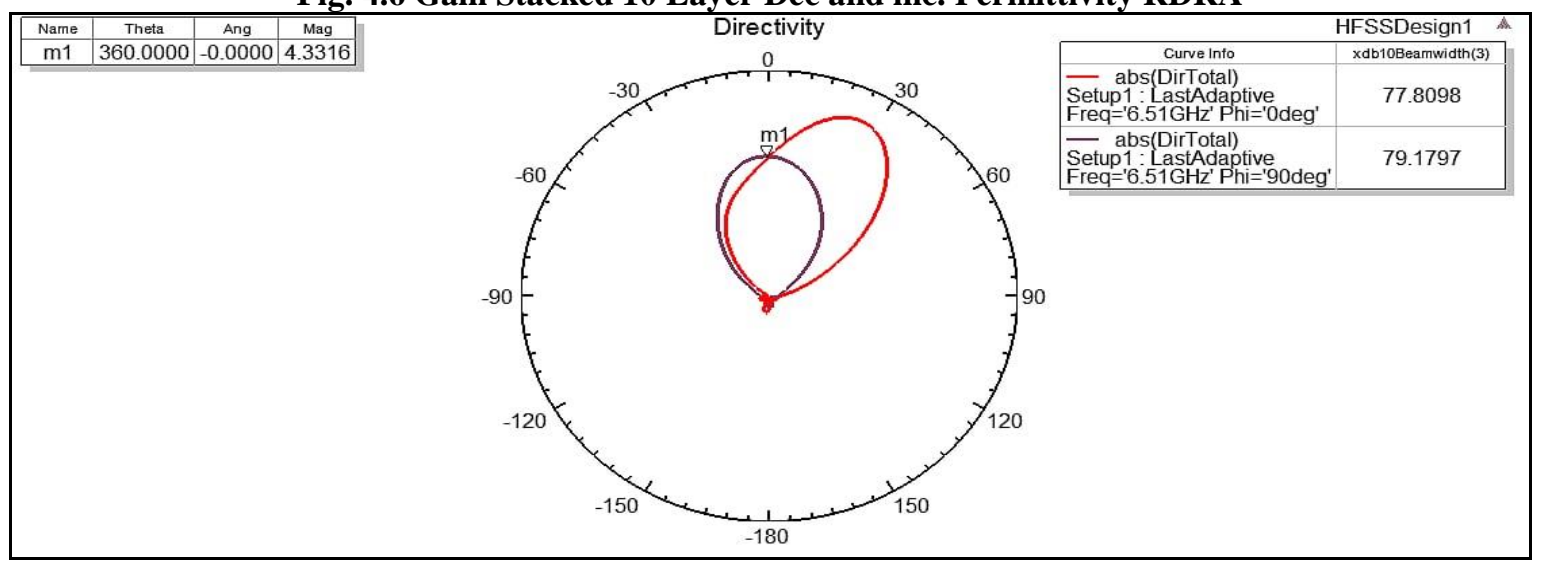

Fig. 4.7 Directivity Stacked 10 Layer Inc. RDRA

DOI Number: https://doi.org/10.30780/specialissue-ICACCG2020/005 
ICACCG2020 30-31 July, 2020, Ansal University, Gurgaon, India

International Journal of Technical Research \& Science (Special Issue)

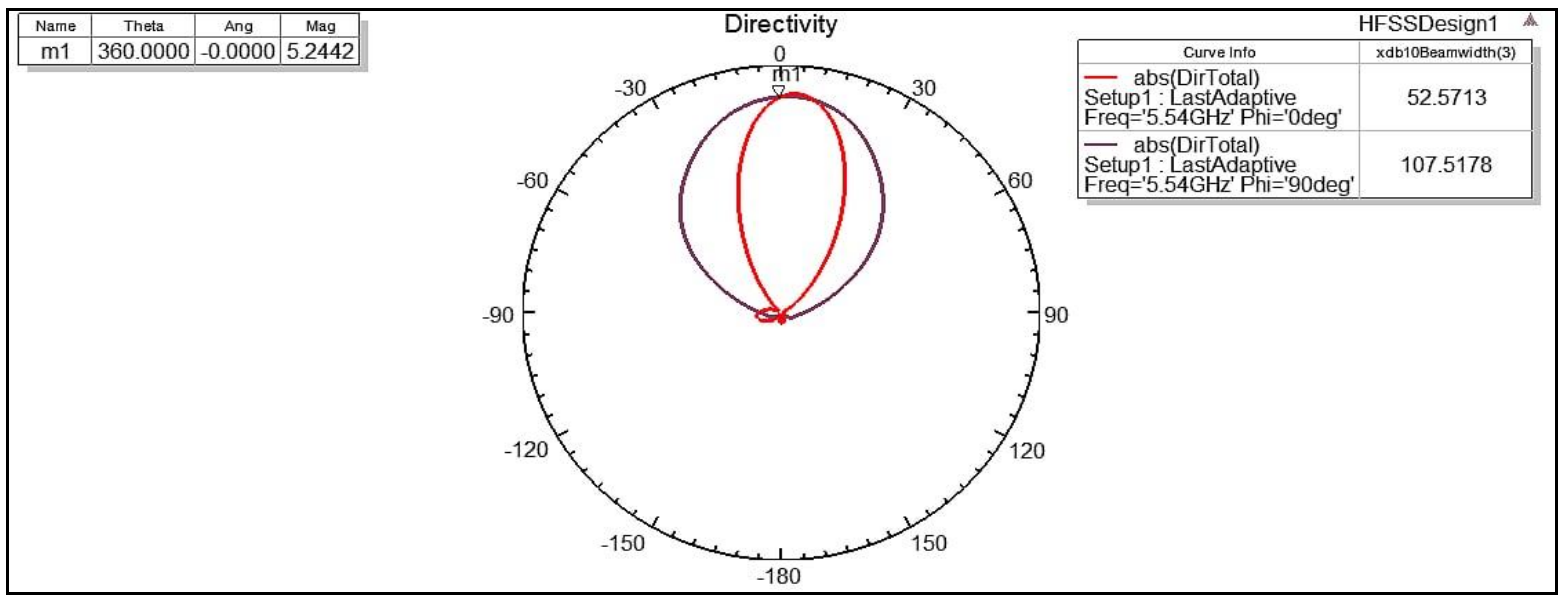

Fig. 4.8 Directivity Stacked 10 Layer Inc. RDRA
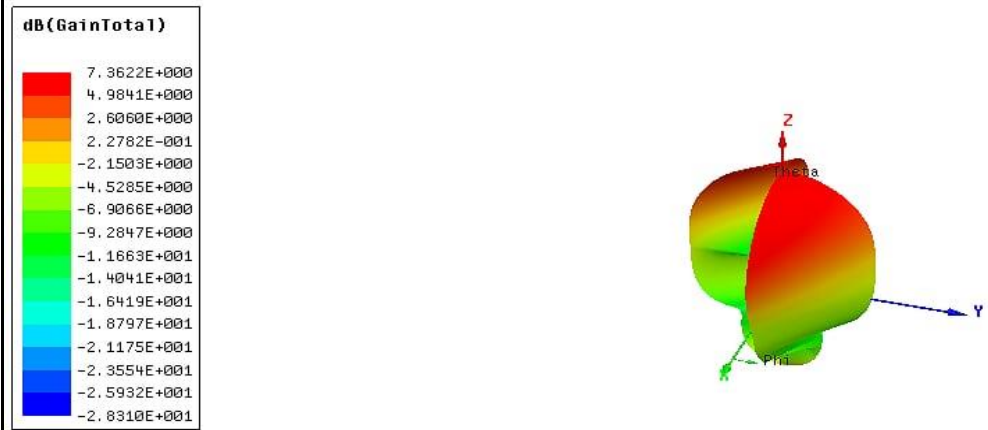

Fig. 4.9 Radiation Pattern Stacked 10 Layer Inc. RDRA
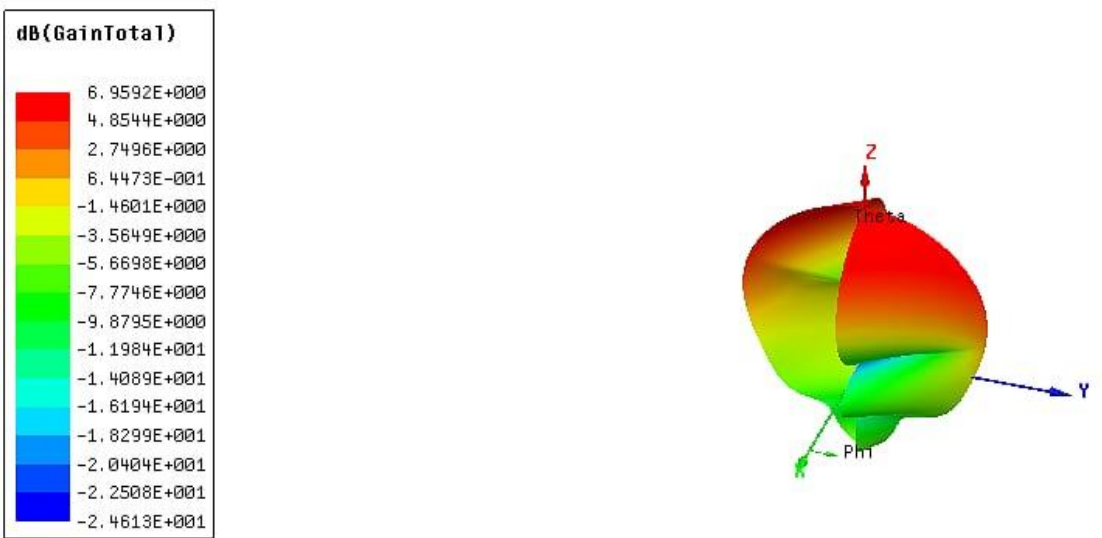

Fig. 4.10 Radiation Pattern Stacked 10 Layer dec . RDRA
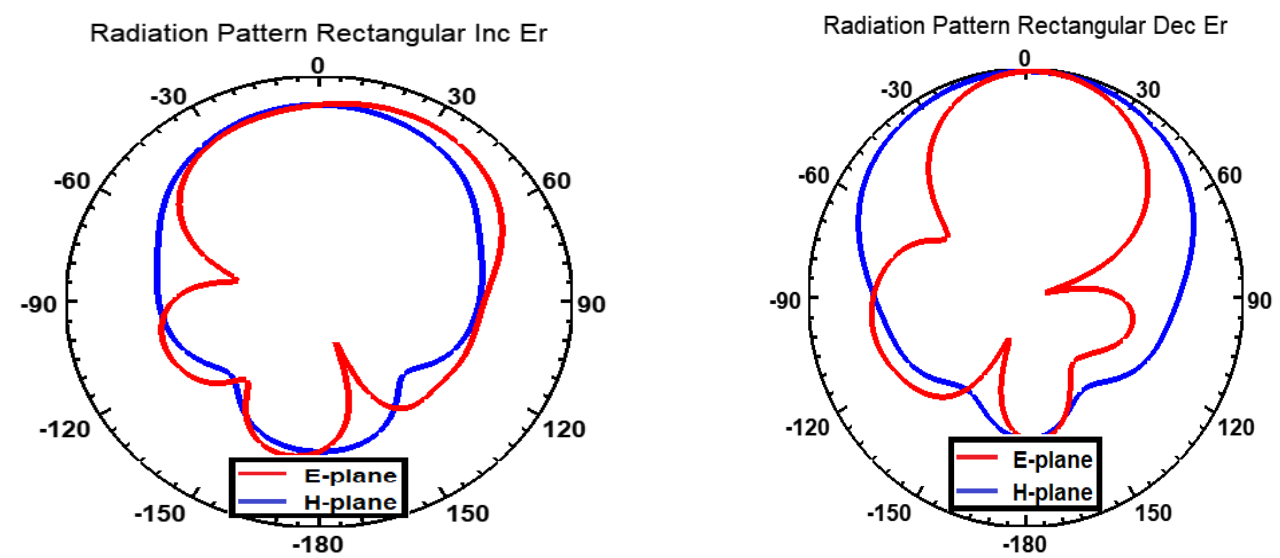

Fig. 4.11 Radiation Pattern Stacked 10 layer dec and inc RDRA

DOI Number: https://doi.org/10.30780/specialissue-ICACCG2020/005

Paper Id: IJTRS-ICACCG2020-005

pg. 32 @ 2017, IJTRS All Right Reserved, www.ijtrs.com 


\section{CONCLUSION}

A comparative analysis for various permittivity stacked geometries rectangular DRA, are presented to extend the gain of the antenna, along to form the beam more directive and hence reducing the beamwidth. 10 layers stacked rectangular geometry with decreasing permittivity presents the best gain $(6.9 \mathrm{dBi})$ compared to the other geometry alongside reasonably controlled beamwidth

\section{REFERENCES}

[1] Sahu, Bhagirath, Mayank Aggarwal, PankajTripathi, and Rajesh Singh. "Stacked cylindrical dielectric resonator antenna with metamaterial as a superstrate for enhancing the bandwidth and gain." In 2013 IEEE international conference on signal processing, computing and control (ISPCC), pp. 1-4. IEEE, 2013.

[2] Kishk, Ahmed A., Ricky Chair, and Kai Fong Lee. "Broadband dielectric resonator antennas excited by Lshaped probe." IEEE Transactions on Antennas and Propagation 54, no. 8 (2006): 2182-2189.

[3] Chair, R., A. A. Kishk, and K. F. Lee. "Experimental investigation for wideband perforated dielectric resonator antenna." Electronics Letters 42, no. 3 (2006): 137-139.

[4] Almpanis G., Fumeaux C. and Vahldieck R., "Novel broadband dielectric resonator antenna fed through double-bowtieslot excitation scheme", ACES Journal, Vol. 22, No. 1, pp. 97-104, 2007.

[5] Li B., and Leung K.W., "Strip-fed rectangular dielectric resonator antennas with/without a parasitic patch", IEEE Transaction Antenna and Propagation", Vol. 41, No. 10, pp. 1390-1398, 1993.

[6] Chair R., Kishk A. A., and Lee K. F., "Wideband simple cylindrical dielectric resonator antenna", IEEE Microwave and Wireless Components Letters, Vol. 15, No. 4, pp. 241-243, 2005.

[7] R. Gupta, R. Yaduvanshi "Embedded cylindrical magneto-hydrodynamic antenna", International Journal of Ultra-wideband Communication, Inderscience, vol. 3, no. 2, pp. 68-72, 2015. ISSN online: 1758-7298.

[8] R. Gupta, R. Yaduvanshi "High gain and wide band Rectangular DRA, International Journal of Ultrawideband Communication", Inderscience, vol. 3, no. 2, pp. 107-114, 2015. ISSN online: 1758-7298.

[9] R. Gupta and R. Yaduvanshi, "Superstrate Embedded Hybrid MHD Antenna" in IEEE International Conference INDICON-2015 ,pp 1-5, 2015, ISBN 978-1-4673-6540-6. 